\title{
Optimization of 3D-Printer Process Parameters for Improving Quality of Polylactic Acid Printed Part
}

\author{
A. E. Tontowi ${ }^{\# 1}$, L. Ramdani ${ }^{\# 2}$, R. V. Erdizon ${ }^{\# 3}$, D. K. Baroroh ${ }^{\# 4}$ \\ \#Department of Mechanical and Industrial Engineering, Faculty of Engineering, \\ Universitas Gadjah Mada, Jl. Grafika 2 Yogyakarta 55281, Indonesia \\ 1alvaedytontowi@ugm.ac.id \\ ${ }^{2}$ lutfi_ramdhani@mail.ugm.ac.id \\ ${ }^{3}$ rosa.vella.e@mail.ugm.ac.id \\ ${ }^{4}$ dawi.karomati.b@mail.ugm.ac.id
}

\begin{abstract}
Technology of 3D-Printer based on fused deposition material has developed intensively with varying qualities. However, default setting of printing process parameters provided by the manufacturer in some cases does not guarantee quality (dimension error and strength) of the printed part, since there are several process parameters that need to be considered. A 3D-Printer with polylactic acid filament material has been applied in this study. A specimen standard of ASTM D638 Type IV has been used as a tensile strength and dimension error test to represent printed part quality. Three printing process parameters: layer thickness $(0.05,0.1$ and $0.15 \mathrm{~mm})$, temperatures $\left(195,200\right.$ and $\left.205^{\circ} \mathrm{C}\right)$ and raster angles $\left(-45^{\circ}, 0^{\circ}\right.$ and $\left.60^{\circ}\right)$ have been optimized using Taguchi and Response Surface Methods. Test was carried out to find the highest tensile strength and the lowest dimension error based on the optimum parameter setting and validated them with experiment and default setting. Quality of printed part obtained by optimum parameter setting of RSM $\left[0.05 \mathrm{~mm}, 199.8^{\circ} \mathrm{C}, 45.1^{\circ}\right]$ showed better than that by Taguchi $[0.15$ $\left.\mathrm{mm}, 195^{\circ} \mathrm{C}, 0^{\circ}\right]$ and default setting $\left[0.1 \mathrm{~mm}, 200^{\circ} \mathrm{C}, 0^{\circ} 0^{\circ}\right.$. In addition, tensile strength of printed part mostly was affected by layer thickness, while dimension error was caused by raster angle.
\end{abstract}

Keyword - 3D-Printer, Optimization, Polylactic Acid (PLA), Taguchi Method, Response Surface Method

\section{INTRODUCTION}

Additive manufacturing (AM) or layer manufacturing (LM) technology and it is called 3D printer has developed intensively with varying material types and forms that can be used to build a 3D object. It is gaining ground for manufacturing prototypes, tools and functional end products [1]. Several of existing technologies include selective laser sintering/melting (SLS/M), laser-photo resin curing (SLA), laser-cutting of sheet material (LOM), fusing of melted filament material (FDM), electron beam melting (EBM) and many others. However, although these technologies have been available commercially, there are a wide range of qualities of the machine and the built part and so the price. Recently, the price of the machine is drop and even a small machineFDM based technology in the kit pack is underway to become home appliances, just like coffee maker. Built part quality of 3D printer (FDM based technology) here is defined on the basis of mechanical strength, surface finish, and dimension error or dimension accuracy. Research related to the mechanical strength of printed parts built by 3D printer can be found in many publications. Tymrak, et.al. investigated tensile strength and modulus elasticity of PLA and ABS parts made by 4 types of open source RepRap 3D printer [2]. They used pattern orientation $\left(0^{\circ} / 90^{\circ},+45^{\circ} / 45^{\circ}\right)$ and layer thickness $(0.2 ; 0.3 ; 0.4 \mathrm{~mm})$ as printing parameters of printing object (ASTM D638). In this research, they found that the mean of tensile strength and modulus elasticity of PLA part were $56.6 \mathrm{MPa}$ and $3368 \mathrm{MPa}$; while for ABS, there were $28.5 \mathrm{MPa}$ and $1807 \mathrm{MPa}$, respectively. In relation to build orientation, Zaldivar et.al found that the orientation also affected thermal behaviour of 3D-Printed ULTEM 9085 Material [3]. By choosing suitable build orientation and reducing layer thickness, Singh Bual and Kumar could improve the surface finish of the printed part [4]. Similar research using FDM has also been done to investigate the combination effect of 5 raster angles $\left(0^{\circ}, 30^{\circ}, 45^{\circ}, 60^{\circ}\right.$ and $\left.90^{\circ}\right)$ and 3 part orientations (horizontal, vertical and perpendicular) to surface roughness, mechanical characteristic (tensile strength and flexural strength) of ABS printed part, production time and cost [5]. They found that raster angle and part orientation gave effect to surface roughness and mechanical characteristic. Among those two parameters, part orientation gave more significant effect than raster angle. In addition, $0^{\circ}$ raster angle, vertical-horizontal part orientation could give lower surface roughness and better mechanical characteristic as well as optimum production time and cost. Moreover, following correlation analysis, layer thickness was effective to improve surface roughness as indicated by inverse relationship between layer thickness and surface roughness [6]. Concerning dimension error or dimension accuracy, there were some publications found. Béraud, et.al. for example, they reported about improving dimensional accuracy of parts produced by Electron Beam Melting EBM) using beam characterization and trajectory optimization [7]. Another research was conducted by Cajal, 
et.al. that introduced a technique to compensate volumetric error for $3 \mathrm{D}$ printers [8]. While concerning dimensional performance for a 3D open-source printer based on fused deposition modelling technique was reported by Galantucci, et.al. [9].

In applying optimization method, several methods have been used by Design of Experiment (DoE) such as Full Factorial Design, Fractional Factorial Design, Taguchi, Response Surface Method (RSM), and other method beside DoE for example Algorithm. Beniak et.al. employed Full Factorial Design to optimize tensile strength of PLA printed part [10]. They used four parameters such as interior filling $(50 \%, 90 \%)$, filling shape (perimeter line, honeycomb), layer size $(0.125 \mathrm{~mm}, 0.25 \mathrm{~mm})$ and model orientation $\left(0^{\circ}, 45^{\circ}\right)$. They found that model orientation and layer thickness have significant effect to minimize production time and quality, specifically tensile strength. Similar method of optimization such as $2 \mathrm{k}$ factorial design method was also applicable to determine optimum parameter of composite [11]. For Fractional Factorial Design, it has been used by Montero, et.al to optimize tensile strength of ABS material (P400). They used five parameters such as raster orientation (transverse, axial), air gap ( 0 in, -0.002 in), road width (0.02 in, 0.0396 in), ABS colour (blue, white), and model temperatures $\left(270^{\circ} \mathrm{C}, 280^{\circ} \mathrm{C}\right)$ [12]. They revealed that the air gap and raster orientation affect the tensile strength of an FDM part, while road width, model temperature, and colour have little effect. The strength of local area in the part merely depends on the raster direction. This occurred because of the nonisotropic behaviour of the parts made by FDM process. In employing Taguchi method with Orthogonal Array L9, this method has been used to optimize process parameters with response dimension accuracy of PLA and ABS printed part built in Wanhao Duplicator 4X machine [13]. They set process parameters such as infill rates $(20 \%, 50 \%$ and $70 \%)$, layer heights $(0.1,0.2$ and $0.3 \mathrm{~mm})$ and number of shells $(1,2$ and 3$)$. In this, a rectangular bulk shape was selected as specimen. For PLA, they found that dimension accuracy could be improved by setting infill rate of $20 \%$ and layer height of $0.2 \mathrm{~mm}$ and shell number of 3 . Applying $0.1 \mathrm{~mm}$ of layer thickness could improve the height, while selecting 1 shell gave better accuracy of length and width, and using 3 shells for height. In RSM utilization, Lanzotti, et.al. used central composite design (CCD) to optimize printing parameter of RepRap Prusa I3 3D printer with response of ultimate tensile strength and fracture strain [14]. Three printing parameters they used including layer thickness, infill orientation and number of shell, also it used specimen of tensile strength follows ASTM D638. Optimum parameter setting was obtained by layer thickness of $0.2 \mathrm{~mm}$, infill orientation of $0^{\circ}$ and 3 shells. This research was done with 2 replications. They found that the mean of ultimate tensile strength was $52.3 \mathrm{MPa}$ and modulus elasticity was $3326 \mathrm{MPa}$. Comparing these results to that predicted by RSM, its tensile strength was $6 \%$ and modulus elasticity was $10.9 \%$ smaller than that obtained by RSM in which its tensile strength and modulus elasticity was $55.6 \mathrm{MPa}$ and $3736 \mathrm{MPa}$, respectively. Similar process (FDM), material (PLA) and method (RSM-CCD), has been conducted by Luzanin, et.al. [15] with different parameters of layer thickness $(0.1 \mathrm{~mm}, 0.2 \mathrm{~mm}$, and $0.3 \mathrm{~mm})$, deposition angles $\left(0^{\circ}\right.$, $30^{\circ}$, and $\left.60^{\circ}\right)$, and infill $(10 \%, 20 \%$, and $30 \%)$. They found similar result that layer thickness has a dominant to get optimum response in FDM-built specimens, and there was any significant interaction between deposition angle and infill. Beside of Design of Experiment (DoE) method, analysis of parameter process can also be done by optimization algorithm. The research with this method was intended to optimize flexural strength, impact strength and tensile strength. Beyond the beneficial by using this method, they need the best primary data input to get the best analysis [16].

Learning from the existing publications above, Taguchi method and RSM were tools of optimization that can be adopted for this current research. Several common printing parameters have also been concerned such as layer thickness, infill rate, density, shell number, raster angle and temperature. The differences between the existing research and present work were the range of layer thickness $(0.05 ; 0.1 ; 0.15 \mathrm{~mm})$, heating temperatures $\left(195 ; 200 ; 205^{\circ} \mathrm{C}\right)$, raster angles $\left(-45^{0} ; 0^{0} ; 60^{\circ}\right)$ and PLA filament of different provider.

\section{Methodology}

\section{A. Materials}

Material used for fabrication specimen was white PLA (Polylactic Acid) filament (produced by Shenzhen Esun Industrial Co., Ltd.) with diameter of $3 \mathrm{~mm}$. This material has operation temperature of $190^{\circ} \mathrm{C}$ to $220^{\circ} \mathrm{C}$.

\section{B. Equipment}

a. 3D printer Wanhao Duplicator 5S Mini.

b. Software Wanhao Maker version 2.3.5.2241 (for converting file *.stl to file *.I).

c. Software Minitab 16 for optimization process.

d. Software Solidworks Premium 2014 for drawing specimen.

e. Digital caliper merk Mitutoyo with accuracy of $0.02 \mathrm{~mm}$ for measuring dimension of the specimen.

f. UTM HT-2402 merk Hung Ta for tensile testing test. 


\section{Specimen and Preparation}

Specimens for tensile strength test (UTS) and dimension error (ED) was fabricated by 3D Printer machine following a specimen standard of ASTM D638 Type IV. Process fabrication was carried out as follows. First, drawing the specimen with geometry and shape (CAD) as described in ASTM D638 Type IV used Solidworks Premium 2014. The CAD was then saved in format of *.stl and exported to Wanhao Maker v.2.3.5.2241 software. In this, the file was converted to format of *.I. Next, the file was ready to be inserted in 3D Printer Wanhao Duplicator 5S Mini for printing based on optimum setting of printing parameters obtained by RSM and Taguchi methods. There were several combination settings of printing process parameters that have been arranged by DoE.

D. Parameters, Levels and Responses

This research was intended to investigate the highest UTS and the lowest ED of printed part as response to varying settings of printing process parameters of the 3D Printer machine. Thus, UTS and ED were selected as responses and noted as $Y_{U T S}$ and $Y_{E D}$, respectively. There were 3 printing process parameters with coded (Table I and II), namely Layer Thickness/LT $(0.05,0.1$ and $0.15 \mathrm{~mm})$, Temperatures/T $\left(195,200\right.$ and $\left.205^{\circ} \mathrm{C}\right)$, and Raster Angles/RA $\left(-45,0\right.$ and $\left.60^{\circ}\right)$ as depicted in Fig 1. Each parameter has 2 levels $(-1$ and +1$)$, while level 0 was selected as base line or default setting. Here, build direction in $\mathrm{Y}$-axis indicates the direction of nozzle movement during rastering.

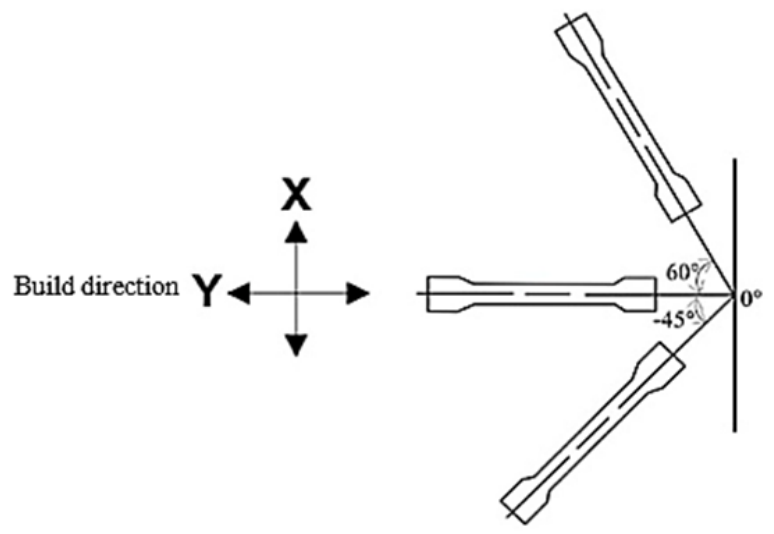

Fig. 1. Raster angles: $-45^{\circ}, 0^{\circ}$ and $60^{\circ}$

Ultimate tensile strength of specimens was determined by applying Eq (1). Data of force $(F)$ was obtained at the Universal Testing Machine (UTM) HT-2402 and cross-section area of the specimen $\left(A_{0}\right)$ was measured directly to the specimen.

$$
U T S=\frac{F}{A_{0}}
$$

where UTS is ultimate tensile strength $\left(\mathrm{N} / \mathrm{mm}^{2}\right), F$ is force at fracture period $(N)$, and $A_{0}$ is cross section area of specimen before fracture $\left(\mathrm{mm}^{2}\right)$. For dimension error $\left(E_{W O}, E_{W}, E_{L O}, E_{t}\right)$ that presented in absolute value, these can be calculated by deploying Eq 2 to 5:

$$
\begin{aligned}
& E_{W O}=\left|\left(\frac{W O_{e x}-W O_{C A D}}{W O_{e x}}\right) 100 \%\right| \\
& E_{W}=\left|\left(\frac{W_{e x}-W_{C A D}}{W_{e x}}\right) 100 \%\right| \\
& E_{L O}=\left|\left(\frac{L O_{e x}-L O_{C A D}}{L O_{e x}}\right) 100 \%\right| \\
& E_{t}=\left|\left(\frac{t_{e x}-t_{C A D}}{t_{e x}}\right) 100 \%\right|
\end{aligned}
$$

where indexes of $L O, W O, W$ and $t, e x$ and $C A D$ indicate dimension error at the length, width, width at narrow part of the specimen, thickness, experiment and reference dimension, respectively.

Since this research involved multiple response problems with contradictive condition i.e. minimizing dimension error and maximizing tensile strength, therefore Grey Relational Method (GRM) was applied and it follows Eq (6) to (10) $[17,18]$ :

a. Grey Relational generation (GRge).

For lower-the-better (LB) criterion can be expressed as:

$$
x_{i}(k)=\frac{\max y_{i}(k)-y_{i}(k)}{\max y_{i}(k)-\min y_{i}(k)}
$$

For higher-the-better (HB) criterion can be expressed as:

$$
x_{i}(k)=\frac{y_{i}(k)-\min y_{i}(k)}{\max y_{i}(k)-\min y_{i}(k)}
$$


b. Grey Relational coefficient (GRc).

$$
\begin{aligned}
& \varepsilon_{i}(k)=\frac{\Delta_{\min }-\varphi \Delta_{\max }}{\Delta_{o, i}(k)-\varphi \Delta_{\max }} \\
& \Delta_{0, i}(k)=\left|x_{i}(k)-x_{i}^{*}(k)\right|
\end{aligned}
$$

c. Grey Relational grade (GRgr).

$$
\gamma_{i}=\frac{1}{n} \sum_{k=1}^{n} \varepsilon_{i}(k)
$$

where $x$ is Grey Relational generation (normalization), $y$ is value of response, index of $i$ is level, $k$ is type of response, $\varepsilon$ is coefficient, $\varphi$ is distinguishing coefficient $(0 \leq \varphi \leq 1), \Delta_{0, i}(k)$ is deviation sequence with $x_{i}{ }^{*}(\mathrm{k})=$ $1, \gamma_{i}$ is weighted average and $n$ is number of response.

Following the Grey Relational analysis $(\hat{\gamma})$, it can be predicted by Eq (11) with confidence interval of prediction $(C I)$ that described in Eq (12) [19]:

$$
\hat{\gamma}=\gamma_{m}+\sum_{i=1}^{q}\left(\overline{\gamma_{l}}-\gamma_{m}\right)
$$

where $\gamma_{m}$ is total mean of the Grey Relational grade, $\overline{\gamma_{l}}$ is mean of optimal level, and $q$ is the number of parameter.

$$
C I=\sqrt{\frac{F_{\alpha ; 1 ; v_{E}}^{M S_{E}}}{n_{\text {eff }}}}
$$

where $F_{\alpha ; 1 ; v_{E}}$ is variability (ANOVA), $M S_{E}$ is mean square error (ANOVA), and $n_{e f f}$ is sum of effective experiment. For significance test, one sample t-test was applied with hypotheses $\mathrm{H}_{0}: \mu=\mathrm{m}_{0}$ and $\mathrm{H}_{1}: \mu \neq \mathrm{m}_{0}$ in $\alpha=5 \%$.

\section{E. Taguchi Method}

In the Taguchi method, orthogonal array $(\mathrm{OA}) \mathrm{L}_{9}$ with 3 replications was used and assumed that each parameter has independent effect or there is no interaction effect to each other. For achieving higher part quality, this method will use orthogonal array, $\mathrm{S} / \mathrm{N}$ ratio and ANOVA analysis adopted from [20]. Table I and II describe parameters and levels of Taguchi method and design of matrix $\mathrm{L}_{9}$.

TABLE I. Parameters and levels of Taguchi method

\begin{tabular}{|l|c|c|c|}
\hline \multirow{2}{*}{\multicolumn{1}{|c|}{ Parameters }} & \multicolumn{4}{c|}{ Levels } \\
\cline { 2 - 4 } & -1 & 0 & +1 \\
\hline Layer Thickness $(\mathrm{LT}) / X_{1}(\mathrm{~mm})$ & 0.05 & 0.1 & 0.15 \\
\hline Temperature $(\mathrm{T}) / X_{2}\left({ }^{\circ} \mathrm{C}\right)$ & 195 & 200 & 205 \\
\hline Raster Angle $(\mathrm{RA}) / X_{3}\left({ }^{\circ}\right)$ & -45 & 0 & 60 \\
\hline Responses are dimension error and tensile strength \\
\hline
\end{tabular}

TABLE II. Design of matrix $\mathrm{L}_{9}$

\begin{tabular}{|c|c|c|c|c|c|c|}
\hline \multirow{2}{*}{ Run } & \multicolumn{3}{|c|}{ Coded Parameters } & \multicolumn{3}{c|}{ Natural Parameters } \\
\cline { 2 - 7 } & $X_{1}$ & $X_{2}$ & $X_{3}$ & $\mathrm{LT}(\mathrm{mm})$ & $\mathrm{T}\left({ }^{\circ} \mathrm{C}\right)$ & $\mathrm{RA}\left({ }^{\circ}\right)$ \\
\hline 1 & -1 & -1 & -1 & 0.05 & 195 & -45 \\
\hline 2 & -1 & 0 & 0 & 0.05 & 200 & 0 \\
\hline 3 & -1 & +1 & +1 & 0.05 & 205 & 60 \\
\hline 4 & 0 & -1 & 0 & 0.1 & 195 & 0 \\
\hline 5 & 0 & 0 & +1 & 0.1 & 200 & 60 \\
\hline 6 & 0 & +1 & -1 & 0.1 & 205 & -45 \\
\hline 7 & +1 & -1 & +1 & 0.15 & 195 & 60 \\
\hline 8 & +1 & 0 & -1 & 0.15 & 200 & -45 \\
\hline 9 & +1 & +1 & 0 & 0.15 & 205 & 0 \\
\hline
\end{tabular}


Results of this analysis are main effect of Average (Ave) and Signal to Noise Ratio (SNR). Experiment was run with 2 types of SNR. For response of dimension error uses principle of smaller is better (Eq 13) and for response of tensile strength applies larger is better (Eq 14).

$$
\begin{aligned}
& S N R_{\text {smaller is better }}=-10 \log \left(\frac{\sum Y^{2}}{n}\right) \\
& S N R_{\text {larger is better }}=-10 \log \left(\frac{\sum \frac{1}{Y^{2}}}{n}\right)
\end{aligned}
$$

where $Y$ is response and $n$ is number of replication.

In this current research, Integrating Taguchi method with Grey Relational Analysis (GRA) was adopted from [21].

\section{F. Response Surface Method (RSM)}

Parameters and responses were used in the RSM are exactly the same as in Taguchi method i.e. 3 parameters and 2 responses. In RSM, there are 2 additional levels $( \pm 1.682)$ and 2 orders. The first order uses Central Composite Design (CCD) that consists of 8 factorial points and 4 center points or 12 points (Run 1-12), while second order consists of 8 factorial points, 6 center points and 6 axial points or 20 points (Run 1-20). Parameters and levels of RSM are shown in Table III and CCD is seen in Table IV.

TABLE III. Parameter of RSM method

\begin{tabular}{|l|c|c|c|c|c|}
\hline \multirow{2}{*}{ Parameters } & \multicolumn{5}{c|}{ Levels } \\
\cline { 2 - 7 } & -1.682 & -1 & 0 & 1 & +1.682 \\
\hline Layer Thickness $(\mathrm{LT}) / X_{1}(\mathrm{~mm})$ & 0.02 & 0.05 & 0.1 & 0.15 & 0.18 \\
\hline Temperature $(\mathrm{T}) / X_{2}\left({ }^{\circ} \mathrm{C}\right)$ & 192 & 195 & 200 & 205 & 208 \\
\hline Raster Angle $(\mathrm{RA}) / X_{3}\left({ }^{\circ}\right)$ & -80.8 & -45 & 0 & 60 & 95.8 \\
\hline Responses are dimension error and tensile strength \\
\hline
\end{tabular}

\begin{tabular}{|c|c|c|c|c|c|c|}
\hline \multirow{2}{*}{\multicolumn{3}{|c|}{ Note }} & \multirow{3}{*}{$\frac{\text { Run }}{1}$} & \multicolumn{3}{|c|}{ Coded Parameters } \\
\hline & & & & \multirow{2}{*}{$\frac{X_{1}}{-1}$} & \multirow{2}{*}{$\frac{X_{2}}{-1}$} & \multirow{2}{*}{$\begin{array}{c}X_{3} \\
-1\end{array}$} \\
\hline \multirow{20}{*}{ 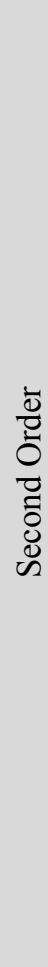 } & \multirow{12}{*}{ 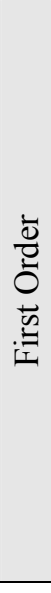 } & \multirow{8}{*}{$\begin{array}{c}\text { Factorial } \\
\text { Points } \\
\text { (nf) }\end{array}$} & & & & \\
\hline & & & 2 & -1 & -1 & 1 \\
\hline & & & 3 & -1 & +1 & -1 \\
\hline & & & 4 & -1 & +1 & +1 \\
\hline & & & 5 & +1 & -1 & -1 \\
\hline & & & 6 & +1 & -1 & 1 \\
\hline & & & 7 & +1 & +1 & -1 \\
\hline & & & 8 & +1 & +1 & +1 \\
\hline & & \multirow{6}{*}{$\begin{array}{c}\text { Center } \\
\text { Points } \\
\text { (nc) }\end{array}$} & 9 & 0 & 0 & 0 \\
\hline & & & 10 & 0 & 0 & 0 \\
\hline & & & 11 & 0 & 0 & 0 \\
\hline & & & 12 & 0 & 0 & 0 \\
\hline & & & 13 & 0 & 0 & 0 \\
\hline & & & 14 & 0 & 0 & 0 \\
\hline & & \multirow{6}{*}{$\begin{array}{c}\text { Axial } \\
\text { Points } \\
\text { (na) }\end{array}$} & 15 & -1.682 & 0 & 0 \\
\hline & & & 16 & +1.682 & 0 & 0 \\
\hline & & & 17 & 0 & -1.682 & 0 \\
\hline & & & 18 & 0 & +1.682 & 0 \\
\hline & & & 19 & 0 & 0 & -1.682 \\
\hline & & & 20 & 0 & 0 & +1.682 \\
\hline
\end{tabular}

TABLE IV. Central composite design (CCD) of RSM 
A sequential order consists of modeling and analysis relationship between responses and independent parameters [22,23]. The first is the use of first-order model (Eq 9). It is a low-order polynomial that expressed as a linear function such as depicted in Eq (15). If there is curvature exist according to its significance of lack of fit test in the system, then second order should be applied, as described in Eq (16) that is a polynomial of higher degree or a quadratic function.

$$
\begin{gathered}
Y_{R}=B_{0}+B_{1} X_{1}+B_{2} X_{2}+\cdots+B_{k} X_{k}+\epsilon \\
Y_{R}=B_{0}+\sum_{i=1}^{k} B_{i} X_{i}+\sum_{i=1}^{k} B_{i i} X^{2}+\sum_{i=1}^{k} \sum_{j=1}^{l} B_{i j} X_{i} X_{j}+\epsilon
\end{gathered}
$$

where $B$ is constant of parameter, $X$ is coded parameter, indexes of $R$ is indicated $L O, W O, W, t, T S ; i=1-k, j=1$ $l$ and $\in$ is error of the model.

\section{A. Optimization Results of Taguchi Method}

\section{RESULTS AND DISCUSSION}

As shown in Table V, there were results of two analysis (Ave and SNR) that have been obtained. There were composed in Rank $(1,2,3)$ and main effects (Ave, SNR) to response dimension error (LO, WO, W, t) and tensile strength (TS). Based on Ave and SNR at the first rank there was found that the mayority of dimension error was affected by raster angle (RA), except the narrow width (WO) that was caused by layer thickness (LT). While tensile strength mostly was caused by layer thickness (LT) as indicated in Table V that LT is the first rank and followed by raster angle (RA) and temperature (T). It was clear that raster angle was important parameter in giving effect to dimension error, whilst layer thickness was more prominent factor to tensile strength rather than temperature. Interesting phenomenon was dimension error at the narrow width $(\mathrm{W}=6 \mathrm{~mm})$ that layer thickness plays important role at this location, but not at another similar location $(\mathrm{WO}=19 \mathrm{~mm})$ that raster angle was more dominant causing dimension error. However, since there was no significant differences between Ave and SNR, depth analysis then should focus on SNR and optimum parameters to response results were shown in Table VI.

TABLE V. Comparison rank of main effect to response

\begin{tabular}{|c|c|c|c|c|c|c|c|c|c|c|}
\hline \multirow{2}{*}{ Rank } & \multicolumn{2}{|c|}{ LO $(\mathrm{mm})$} & \multicolumn{2}{c|}{ WO $(\mathrm{mm})$} & \multicolumn{2}{c|}{ TS $\left(\mathrm{N} / \mathrm{mm}^{2}\right)$} & \multicolumn{2}{c|}{$\mathrm{W}(\mathrm{mm})$} & \multicolumn{2}{c|}{$\mathrm{t}(\mathrm{mm})$} \\
\cline { 2 - 12 } & Ave & SNR & Ave & SNR & Ave & SNR & Ave & SNR & Ave & SNR \\
\hline 1 & RA & RA & LT & LT & LT & LT & RA & RA & RA & RA \\
\hline 2 & LT & LT & T & T & RA & RA & T & T & LT & LT \\
\hline 3 & T & T & RA & RA & T & T & LT & LT & T & T \\
\hline
\end{tabular}

TABLE VI. Composition of parameter to optimum response (SNR)

\begin{tabular}{|l|l|l|}
\hline \multirow{4}{*}{$\begin{array}{l}\text { Dimension } \\
\text { error }\end{array}$} & Length (LO) & LT $(0.15 \mathrm{~mm}), \mathrm{T}\left(200^{\circ} \mathrm{C}\right)$, RA $\left(0^{\circ}\right)$ \\
\cline { 2 - 3 } & Width (WO) & LT $(0.05 \mathrm{~mm}), \mathrm{T}\left(195^{\circ} \mathrm{C}\right)$, RA $\left(-45^{\circ}\right)$ \\
\cline { 2 - 3 } & Width at Narrow (W) & LT $(0.05 \mathrm{~mm}), \mathrm{T}\left(205^{\circ} \mathrm{C}\right)$, RA $\left(60^{\circ}\right)$ \\
\cline { 2 - 3 } & Thickness (t) & LT $(0.1 \mathrm{~mm}), \mathrm{T}\left(200^{\circ} \mathrm{C}\right)$, RA $\left(-45^{\circ}\right)$ \\
\hline \multicolumn{2}{|l|}{ Tensile Strength (TS) } & LT $(0.15 \mathrm{~mm}), \mathrm{T}\left(195^{\circ} \mathrm{C}\right)$, RA $\left(0^{\circ}\right)$ \\
\hline
\end{tabular}

Analysis of optimum response which was conducted by SNR showed in Table V that there were variation level values of each parameter for all responses of dimension error. Combination level of optimum parameter for length error (LO) was almost the same as tensile strength (TS), except its temperature that was lower $\left(\mathrm{T}=195^{\circ} \mathrm{C}\right)$. In practical work, setting process parameter was only taken at once before the 3D Printer machine was run for printing of part. Therefore, it was only one suggested parameter set to be selected, either based on TS $\left(\mathrm{LT}=0.15 \mathrm{~mm}, \mathrm{~T}=195^{\circ} \mathrm{C}, \mathrm{RA}=0^{\circ}\right.$ ) or one from among the error dimensions such as $\mathrm{LO}(\mathrm{LT}=0.15 \mathrm{~mm}$, $\mathrm{T}=200^{\circ} \mathrm{C}, \mathrm{RA}=0^{\circ}$ ). This selected parameter set could be implemented, as temperature set of $195^{\circ} \mathrm{C}$ or $200^{\circ} \mathrm{C}$ did not give significant effect to tensile strength or dimension error of length, as T position was in Rank 3 (Table V).

In actual condition, multiple responses could be affected by combination parameters (not a single parameter), thus Grey Relational Method (GRM) with 3 steps need to be applied (Eq 6 to 10). Results could be seen in Table VII, and Fig 2. It was found that raster angle (Rank 1) affected dimension error, followed by temperature (Rank 2) and layer thickness (Rank 3). The real values of optimum parameters setting based on Grey Relational grade $(\mathrm{GRg})$, namely LT $=0.664(0.15 \mathrm{~mm}), \mathrm{T}=0.698\left(200^{\circ} \mathrm{C}\right)$, and $\mathrm{RA}=0.669\left(60^{\circ}\right)$. 
TABLE VII. Overall grey relational coefficient (GRc)

\begin{tabular}{|c|c|c|c|c|c|}
\hline \multirow{2}{*}{ Run } & \multicolumn{5}{|c|}{ Grey Relational coefficient $(\varphi=0.5)$} \\
\cline { 2 - 6 } & LO & WO & $\mathrm{t}$ & $\mathrm{W}$ & TS \\
\hline 1 & 0.438 & 0.333 & 0.464 & 0.517 & 0.367 \\
\hline 2 & 0.504 & 0.976 & 0.906 & 1.000 & 0.567 \\
\hline 3 & 1.000 & 0.464 & 0.571 & 0.333 & 0.333 \\
\hline 4 & 0.442 & 0.506 & 0.593 & 0.646 & 0.697 \\
\hline 5 & 0.544 & 1.000 & 0.333 & 0.667 & 0.501 \\
\hline 6 & 0.454 & 0.797 & 0.461 & 0.718 & 0.445 \\
\hline 7 & 0.645 & 0.882 & 1.000 & 0.591 & 0.800 \\
\hline 8 & 0.371 & 0.939 & 0.356 & 0.775 & 0.598 \\
\hline 9 & 0.333 & 0.802 & 0.483 & 0.788 & 1.000 \\
\hline
\end{tabular}

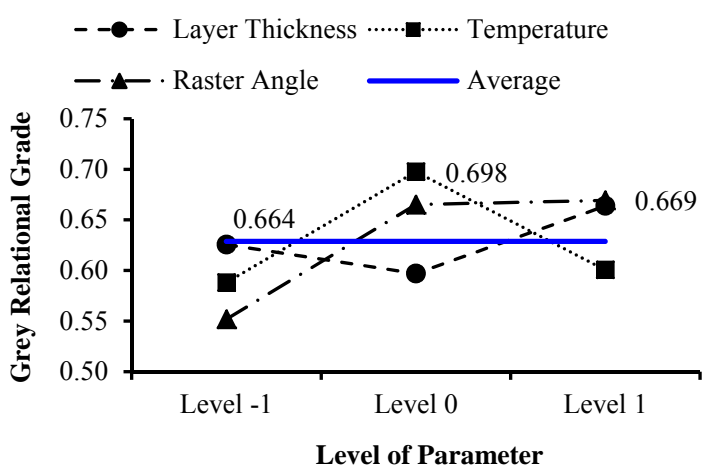

Fig. 2. GR grade for each level of parameter (dimension error)

By inserting $\gamma_{m}=6.29$ and $\overline{\gamma_{l}}=0.664,0.698$ and 0.669 to Eq (11), then prediction for optimum combination was $\hat{\gamma}=0.773$ with confidence interval $\mathrm{CI}= \pm 0.0272$ (in $\alpha=5 \%$ ). The value of 0.773 was equal meaning to percentage of predicted dimension error seen in Fig 3.

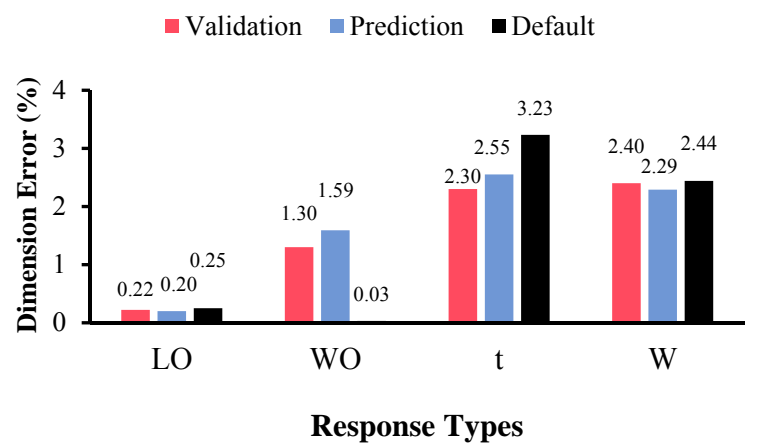

Fig. 3. Dimension error vs response types (Taguchi method)

In Fig 3 here, differences in dimension error were highly visible in thickness error ( $t$ ) and width at narrow error (W). Comparing to the prediction and the validation (Taguchi), default setting provided higher dimension error. From analysis one sample t-test for thickness error, there was not significant difference between validation and model prediction $\left(\mathrm{P}_{\text {value }}=0.108\right)$. The same thing also occurs for error of width at narrow $(\mathrm{W})$. The validation and default setting was also not significantly different $\left(\mathrm{P}_{\text {value }}=0.225>0.05\right)$. It means failed to reject Ho or that validation, prediction and default were no significant differences.

Similar to the dimension error, tensile strength seen in Fig 4 was primary affected by layer thickness as indicated at rank-1, followed by raster angle at rank-2 and temperature at the rank-3. This depicts different view to that of dimension error that raster angle was prominent factor. Looking at Fig 4, the optimum parameter setting for tensile strength predicted by Taguchi method and Grey Relational method was layer thickness $\mathrm{LT}=0.799(0.15 \mathrm{~mm}), \mathrm{T}=0.621\left(195^{\circ} \mathrm{C}\right)$ and $\mathrm{RA}=0.755\left(0^{\circ}\right)$. 


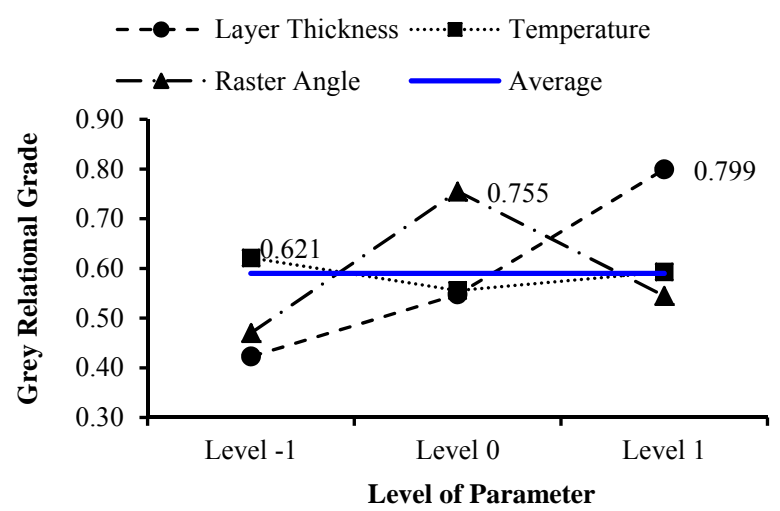

Fig. 4. GR grade for each level of parameter (tensile strength)

Applying GR grade $\gamma_{m}=5.90, \bar{\gamma}_{l}=0.621,0.755$ and 0.799 to Eq (11), the prediction for optimum combination was: $\hat{\gamma}=0.995$ with confidence interval $\mathrm{CI}= \pm 0.0355$ (in $\alpha=5 \%$ ). The GRgr value of 0.995 was equal to the prediction of tensile strength of $48.90 \mathrm{~N} / \mathrm{mm}^{2}$ as shown in Fig 5 .

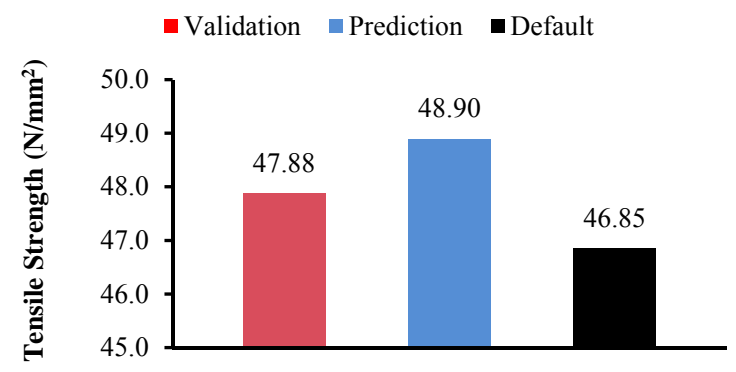

Fig. 5. Analysis of tensile strength (Taguchi)

Prediction of tensile strength obtained by Taguchi gave higher value than validation or default setting. However, based on the analysis one sample t-test, there were not significant differences between prediction, validation and default setting with $\mathrm{P}_{\text {value }}$ was higher than 0.05 or failed to reject Ho. Following the whole optimization analysis of printing parameter setting that have been carried out by Taguchi and compare it to default, it could be concluded that Taguchi could improve quality of printed part with optimum parameter setting of the 3D Printer. Although, Taguchi was not able to show optimum combination of multiple responses as occur in actual condition, but it could be improved by Grey Relational Analysis Method.

\section{B. Optimization Results of Response Surface Method (RSM)}

In RSM, there were 2 steps procedures i.e. first and second orders. The first order of RSM was carried out to predict responses as an effect of parameters using Eq (15) and the results are shown in Eq (17) to (21) and curvature test and lack of fit test of RSM of first order are depicted in Table VIII.

$$
\begin{aligned}
& Y_{L O}=0.27-0.022 X_{1}-0.0024 X_{2}+0.199 X_{3} \\
& Y_{W O}=0.48+0.092 X_{1}+0.066 X_{2}+0.265 X_{3} \\
& Y_{T}=1.36-0.45 X_{1}-0.418 X_{2}-0.317 X_{3} \\
& Y_{W}=3.38-0.233 X_{1}+0.149 X_{2}+1.176 X_{3} \\
& Y_{T S}=43.52-0.999 X_{1}+0.289 X_{2}+2.055 X_{3}
\end{aligned}
$$

TABLE VIII. Curvature and lack of fit test (first order)

\begin{tabular}{|c|c|c|}
\hline Response & Curvature Test & Lack of Fit Test \\
\hline LO & 0.518 & 0.980 \\
\hline WO & 0.356 & 0.280 \\
\hline T & 0.827 & 0.301 \\
\hline W & 0.092 & 0.630 \\
\hline TS & 0.000 & 0.044 \\
\hline
\end{tabular}


Based on Table VIII, analysis curvature and lack of fit from all of responses (LO, WO, T, W and TS), one of response (TS) was not fulfill to the first order of linear model, because curvature test $(0.000)$ and lack of fit test $(0.044)$ were below $5 \%(\alpha)$. It means that reject Ho or there was non-linear or curvature exists in the model or any interaction in this effect of parameter setting. Therefore, analysis of second order was needed.

Similar to the first order of RSM, software Minitab was used to obtain second order of RSM for predicting model effect of parameter as shown in Eq (22) to (26) and lack of fit test as seen in Table IX.

$Y_{L O}=0.26-0.027 X_{1}-0.009 X_{2}+0.154 X_{3}+0.006 X_{1}{ }^{2}+0.022 X_{2}{ }^{2}-0.008 X_{3}{ }^{2}-0.002 X_{1} X_{2}-0.01 X_{1} X_{3}-$ $0.003 X_{2} X_{3}$

$Y_{W O}=0.35-0.001 X_{1}+0.04 X_{2}+0.17 X_{3}-0.001 X_{1}{ }^{2}+0.05 X_{2}{ }^{2}+0.05 X_{3}{ }^{2}+0.08 X_{1} X_{2}+0.065 X_{1} X_{3}+$ $0.008 X_{2} X_{3}$

$Y_{T}=1.92-0.21 X_{1}-0.16 X_{2}-0.3 X_{3}-0.36 X_{1}^{2}+0.053 X_{2}{ }^{2}-0.4 X_{3}{ }^{2}-0.3 X_{1} X_{2}-0.49 X_{1} X_{3}+$ $0.48 X_{2} X_{3}$

$Y_{W}=2.73-0.22 X_{1}+0.07 X_{2}+0.55 X_{3}+0.26 X_{1}{ }^{2}+0.031 X_{2}{ }^{2}+0.38 X_{3}{ }^{2}-0.17 X_{1} X_{2}-0.32 X_{1} X_{3}-$

$0.07 X_{2} X_{3}$

$Y_{T S}=49.55-1.56 X_{1}+0.22 X_{2}+3.09 X_{3}+3.51 X_{1}^{2}+1.33 X_{2}^{2}-2.11 X_{3}^{2}-0.065 X_{1} X_{2}+$

$0.38 X_{1} X_{3}-0.46 X_{2} X_{3}$

Second order was a model that combining between linear model $\left(X_{1}, X_{2}, X_{3}\right)$ shown in first order in Eq (17) to (21), interaction $\left(X_{1} X_{2}, X_{1} X_{3}, X_{2} X_{3}\right)$ and quadratic $\left(X_{1}^{2}, X_{2}^{2}, X_{3}^{2}\right)$ shown in Eq (22) to (26). Because of second order was model of non-linear, so that curvature test was not needed. While analysis lack of fit test was needed to know correlation model with data. Based on Table IX, $\mathrm{P}_{\text {value }}$ from all of second order model were higher than $\alpha(5 \%)$. It means that failed to reject Ho or the second order model was fit to described data.

TABLE IX. Lack of fit test (second order)

\begin{tabular}{|c|c|}
\hline Response & Lack of Fit Test \\
\hline LO & 0.087 \\
\hline WO & 0.107 \\
\hline $\mathrm{t}$ & 0.604 \\
\hline $\mathrm{W}$ & 0.059 \\
\hline $\mathrm{TS}$ & 4.120 \\
\hline
\end{tabular}

Since the second order was fit to the data, then it continuous to the next step i.e. to find the combination level and parameter for optimum response using response optimizer in Minitab 15. It was found that the optimum combination for response of dimension error were $0.04 \mathrm{~mm}$ for layer thickness, $201^{\circ} \mathrm{C}$ for temperature and $80.6^{\circ}$ for raster angle. Fig 6 shows comparison between prediction, validation and default setting.

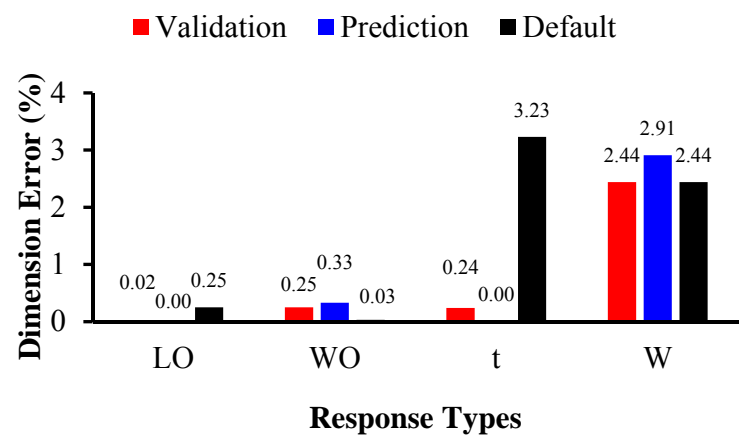

Fig. 6. Dimension error vs response types (RSM method)

Among 4 response types of dimension error (\%) seen in Fig 6, thickness error $(\mathrm{t})$ showed highly differences between prediction $(0.00 \%)$, validation $(0.24 \%)$ and default $(3.23 \%)$. However, if we look at the whole response types of dimension error (LO, WO and W), according to analysis one sample t-test, there was not significant difference between validation and prediction $\left(\mathrm{P}_{\text {value }}=0.263>0.05\right.$ or failed to reject Ho, and there was significant difference between validation and default setting $\left(\mathrm{P}_{\text {value }}=0.004<0.05\right.$ or reject Ho). In term of dimension error, it was clear that RSM could significantly reduce dimension error and it was better comparing to Taguchi and default setting. 
Regarding tensile strength, RSM prediction that has been done in Minitab 15 and the results was seen in Fig 7 revealed that optimum combination of response (LT, T, RA) for tensile strength were -0.1869 (coded variable) or equal to $0.09 \mathrm{~mm}$ for layer thickness, -0.051 (coded variable) or equal $199.8^{\circ} \mathrm{C}$ for temperature and 0.7154 (coded variable) or equal to $45.1^{\circ}$ for raster angle. This combination of parameters gave a maximum prediction tensile strength of $50.80 \mathrm{~N} / \mathrm{mm}^{2}$. If this tensile strength prediction was compared to that of validation and default parameter setting as depicted in Fig 8, prediction was higher than that of validation $\left(49.04 \mathrm{~N} / \mathrm{mm}^{2}\right)$ and default setting $\left(46.85 \mathrm{~N} / \mathrm{mm}^{2}\right)$. There was also no significant difference between prediction and validation as indicated by analysis one sample t-test $\left(\mathrm{P}_{\text {value }}=0.067>0.05\right.$ or failed to reject Ho, but there was significant difference between validation and default setting $\left(\mathrm{P}_{\text {value }}=0.045<0.05\right.$ or reject $\left.\mathrm{Ho}\right)$.

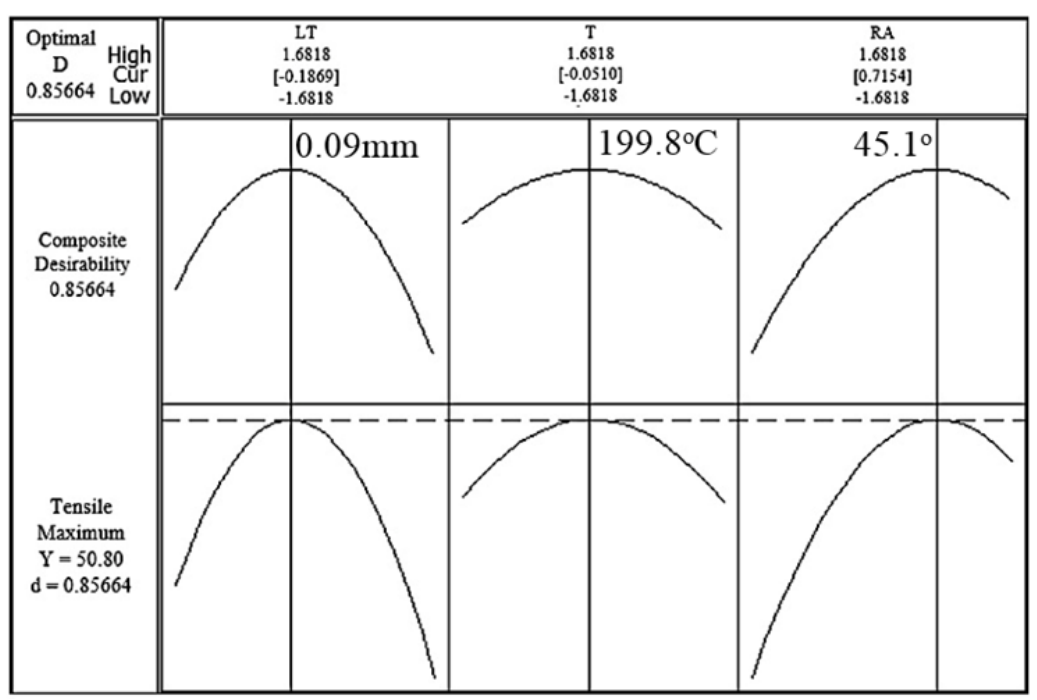

Fig. 7. Prediction of tensile strength (RSM method) obtained by Minitab 15

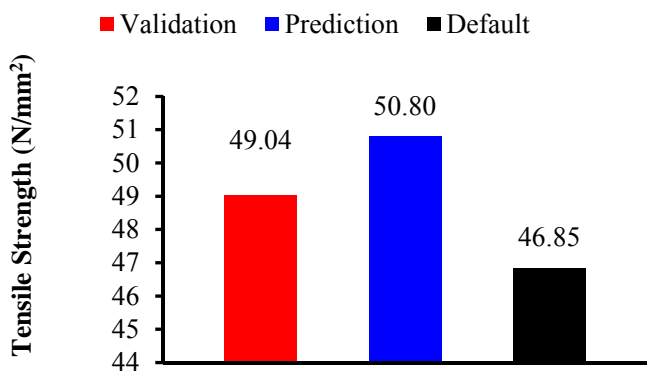

Fig. 8. Tensile strength of prediction, validation and default (RSM method)

Fig 9 and 10 figure out dimension errors and tensile strengths obtained by optimum parameter setting (Taguchi and RSM), validation and default setting recommended by 3D Printer factory. In optimizing printing parameters (layer thickness, temperatures and raster angles) with ultimate goal was a better printed part quality (dimension error and tensile strength), optimum parameter setting obtained by Taguchi method could only show significant improvement in tensile strength and but not in dimension error, whilst RSM method could effectively improve both tensile strength and dimension error.

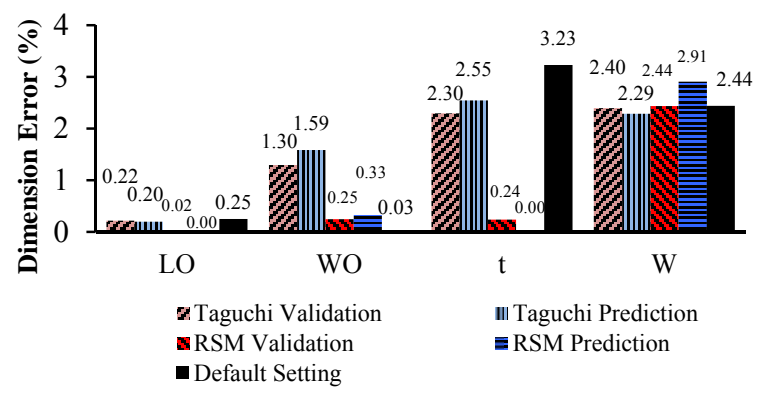

Fig. 9. Dimension error obtained by Taguchi, RSM and default setting 
Comparing 2 optimization methods for obtaining optimum parameter setting which conducted by Taguchi and RSM, as well as default setting as a control, RSM reveals lower dimension error for 3 responses (LO, WO, t) than that of Taguchi method and default setting. While for dimension error of width at narrow (W), Taguchi method shows oppositely i.e. lower than that of RSM and default setting. For tensile strength, moreover, RSM also presented higher prediction values $\left(50.80 \mathrm{~N} / \mathrm{mm}^{2}\right)$ compared to Taguchi method prediction $\left(48.90 \mathrm{~N} / \mathrm{mm}^{2}\right)$ and default setting $\left(46.85 \mathrm{~N} / \mathrm{mm}^{2}\right)$.

Noted also that tensile strength was prominently affected by layer thickness, rather than raster angle or temperature. It could be understood that the 3D Printer machine was already set up with density of $100 \%$ and thus changing the raster angle did not give effect to the density as representation of tensile strength. It is also temperature setting of 195,200 and $205^{\circ} \mathrm{C}$. By changing temperature with $5^{\circ} \mathrm{C}$ of differences does not affect to the tensile strength as well since those temperatures were still in the range of operational temperature of PLA filament $\left(190-220^{\circ} \mathrm{C}\right)$. Concerning analyses of one sample t-test for RSM and Taguchi method, particularly validation values that taken from the actual experiment, found that $\mathrm{P}_{\text {value }}=0.000(<5 \%)$ or reject Ho for both responses. It was indicated that value of two responses (dimension error and tensile strength), RSM gave results significantly different to Taguchi method. It was clear that RSM was considered better method in finding optimum printing parameter setting than Taguchi and default setting. This was in agreement theoretically to RSM that RSM wasable to generate global optimum as RSM was known as systemic prosedures for building model which adaptable with pattern data (linear/non linear) [22].

In printed part quality, tensile strength improvement of printed part based on optimum parameter setting of Taguchi and RSM were $4 \%$ and $8 \%$ better than default. Similarly for dimension error, RSM and Taguchi improvement were in the range of 19 to $100 \%$ and 6 to $21 \%$, respectively.

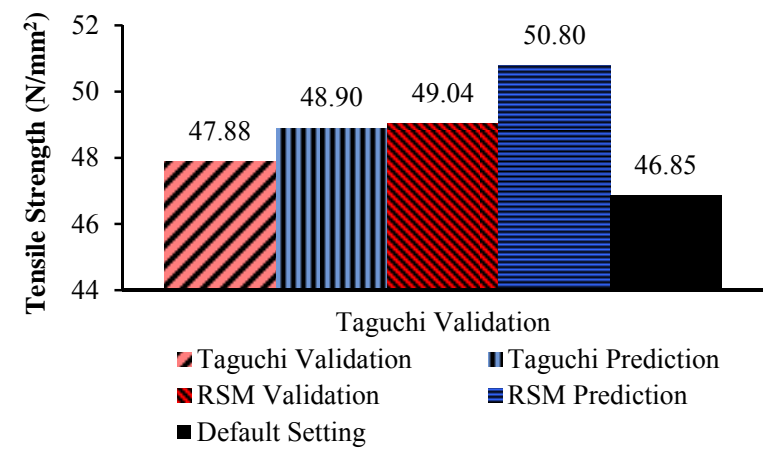

Fig. 10. Tensile strength obtained by Taguchi, RSM and default setting

\section{CONCLUSION}

Printing process parameterof 3D Printer with 2 levels (layer thickness/LT, temperature/T and raster angle/RA) has been optimized to determine quality of printed part (the highest tensile strength and the lowest dimension error). Two methods of optimization were applied including Taguchi method and RSM. As a comparator was the results of the default setting [LT $=0.1 \mathrm{~mm}, \mathrm{~T}=200^{\circ} \mathrm{C}, \mathrm{RA}=0^{\circ}$ ] recommended by manufacturer. RSM revealed optimum parameter setting of $\left[\mathrm{LT}=0.09 \mathrm{~mm}, \mathrm{~T}=199.8^{\circ} \mathrm{C}, \mathrm{RA}=45.1^{\circ}\right]$ and Taguchi of $\left[\mathrm{LT}=0.15 \mathrm{~mm}, \mathrm{~T}=195^{\circ} \mathrm{C}, \mathrm{RA}=0^{\circ}\right]$. RSM gave better prediction of tensile strength $\left(50.80 \mathrm{~N} / \mathrm{mm}^{2}\right)$ and dimension error than that of Taguchi $\left(48.90 \mathrm{~N} / \mathrm{mm}^{2}\right)$ and default setting $\left(46.85 \mathrm{~N} / \mathrm{mm}^{2}\right)$. Tensile strength mostly was affected by layer thickness, while dimension error was dominantly affected by raster angle. Comparing to default setting, tensile strength improvement of printed part based on optimum parameter setting of Taguchi and RSM were $4 \%$ and $8 \%$ better than default. Similarly for dimension error, Taguchi and RSM improvement were in the range of $6-21 \%$ and $19-100 \%$, respectively. This optimum parameter setting obtained by RSM can potentially be implemented in 3D Printer machine with PLA as a filament material, except the raster angle as the direction of printing movement is fixed in Y-axis or at $0^{\circ}$ of raster angle. While in reality, printed part with complex geometry and shape could be in any orientation angles that impossible to be printed in current 3D printer machine with fixed printing movement.

\section{ACKNOWLEDGMENT}

This research was funded by Research Grant of Department of Mechanical and Industrial Engineering Faculty of Engineering UGM and Research Grant UGM No.738/UN1-P.III/LIT/DIT-LIT/2016. For those the authors acknowledge. 


\section{REFERENCES}

[1] J. P. Kruth, G. Levy, F. Klocke, and T. H. C. Childs, "Consolidation phenomena in laser and powder-bed based layered manufacturing," CIRP Ann. - Manuf. Technol., vol. 56, no. 2, pp. 730-759, 2007.

[2] B. M. Tymrak, M. Kreiger, and J. M. Pearce, "Mechanical properties of components fabricated with open-source 3-D printers under realistic environmental conditions," Mater. Des., vol. 58, pp. 242-246, 2014.

[3] R. J. Zaldivar, D. B. Witkin, T. McLouth, D. N. Patel, K. Schmitt, and J. P. Nokes, "Influence of processing and orientation print effects on the mechanical and thermal behavior of 3D-Printed ULTEM?? 9085 Material," Addit. Manuf., vol. 13, pp. 71-80, 2017.

[4] G. Singh Bual and P. Kumar, "Methods to Improve Surface Finish of Parts Produced by Fused Deposition Modeling," Manuf. Sci. Technol., vol. 2, no. 3, pp. 51-55, 2014.

[5] I. Durgun and R. Ertan, "Experimental investigation of FDM process for improvement of mechanical properties and production cost," Rapid Prototyp. J., vol. 20, no. 3, pp. 228-235, 2014.

[6] R. Anitha, S. Arunachalam, and P. Radhakrishnan, "Critical parameters influencing the quality of prototypes in fused deposition modelling," J. Mater. Process. Technol., vol. 118, no. 1-3, pp. 385-388, 2001.

[7] N. Béraud, F. Vignat, F. Villeneuve, and R. Dendievel, "Improving Dimensional Accuracy in EBM using Beam Characterization and Trajectory Optimization," Addit. Manuf., vol. 14, pp. 1-6, 2016.

[8] C. Cajal, J. Santolaria, J. Velazquez, S. Aguado, and J. Albajez, "Volumetric error compensation technique for 3D printers," Procedia Eng., vol. 63, pp. 642-649, 2013.

[9] L. M. Galantucci, I. Bodi, J. Kacani, and F. Lavecchia, "Analysis of Dimensional Performance for a 3D Open-source Printer Based on Fused Deposition Modeling Technique," Procedia CIRP, vol. 28, pp. 82-87, 2015.

[10] J. Beniak, P. Križan, M. Matúš, and L. Šooš, "Experiment on production time for model creation on small fused deposition modeling device," Int. J. Mech., vol. 9, pp. 138-144, 2015.

[11] A. E. Tontowi and D. A. Putra, "Effect of Sericin in [ HA / Bioplastic ] Composite Composed by 2 k Factorial Design Method on Solidification Time and Tensile Strength,” Int. J. Eng. Technol., vol. 7, no. 5, pp. 1943-1951, 2015.

[12] M. Montero, S. Roundy, and D. Odell, "Material characterization of fused deposition modeling (FDM) ABS by designed experiments," Proc. Rapid Prototyp. Manuf. Conf., pp. 1-21, 2001.

[13] Z. Moza, K. Kitsakis, J. Kechagias, and N. Mastorakis, "Optimizing Dimensional Accuracy of Fused Filament Fabrication using Taguchi Design," 14th Int. Conf. Instrumentation, Meas. Circuits Syst., pp. 110-114, 2015.

[14] A. Lanzotti, M. Grasso, G. Staiano, and M. Martorelli, "The impact of process parameters on mechanical properties of parts fabricated in PLA with an open-source 3-D printer," Rapid Prototyp. J., vol. 21, no. 5, pp. 604-617, 2015.

[15] O. Lužanin, D. Movrin, and M. Plan, "Effect of Layer Thickness, Deposition Angle, and Infill on Maximum Flexural Force in FdmBuilt Specimens,” J. Technol. Plast., vol. 39, no. 1, pp. 49-58, 2014.

[16] R. V. Rao and D. P. Rai, "Optimization of fused deposition modeling process using teaching-learning-based optimization algorithm," Eng. Sci. Technol. an Int. J., vol. 19, no. 1, pp. 587-603, 2016.

[17] S. Datta and S. S. Mahapatra, "Modeling, simulation and parametric optimization of wire EDM process using response surface methodology coupled with grey-Taguchi technique,” Multicr. Int. J. Eng. Sci. Technol. Ext., vol. 2, no. 5, pp. 162-183, 2010.

[18] J. L. Lin and C. L. Lin, "The use of the orthogonal array with grey relational analysis to optimize the electrical discharge machining process with multiple performance characteristics," Int. J. Mach. Tools Manuf., vol. 42, no. 2, pp. 237-244, 2002.

[19] P. J. Ross, “Taguchi Techniques for Quality Engineering," Loss Fuction, Orthogonal Exp. Param. Toler. Des., no. February 2015, p. 279,1998

[20] K. P. K. Vishal N. Patel, "Parametric Optimization of The Process of Fused Deposition Modeling In Rapid Prototyping Technology- A Review,” Int. J. Innov. Res. Sci. Technol., vol. 1, no. 7, pp. 80-82, 2014.

[21] C. C. Wang, T.-W. Lin, and S.-S. Hu, "Optimizing the rapid prototyping process by integrating the Taguchi method with the Gray relational analysis,” Rapid Prototyp. J., vol. 13, no. 5, pp. 304-315, 2007.

[22] J. T. Horng, N. M. Liu, and K. T. Chiang, "Investigating the machinability evaluation of Hadfield steel in the hard turning with Al2O3/TiC mixed ceramic tool based on the response surface methodology,” J. Mater. Process. Technol., vol. 208, no. 1-3, pp. 532$541,2008$.

[23] D. C. Montgomery, Design and Analysis of Experiments Eighth Edition. 2013.

\section{AUTHOR PROFILE}

Alva Edy Tontowi is an Associate Professor at the Department of Mechanical and Industrial Engineering, Faculty of Engineering, Universitas Gadjah Mada. His research interest areas are design, biomaterials and additive manufacturing.

Lutfi Ramdani is a bachelor engineering in Industrial Engineering. His research interest area is optimization of manufacturing process, particularly $3 \mathrm{D}$ printer.

Rosa Vella Erdizon is a bachelor engineering in Industrial Engineering. Her research interest area is optimization of manufacturing process of polymer.

Dawi Karomati Baroroh is researcher at the Department of Mechanical and Industrial Engineering, Faculty of Engineering, Universitas Gadjah Mada. Her research interest areas are design, optimization and manufacturing system. 